
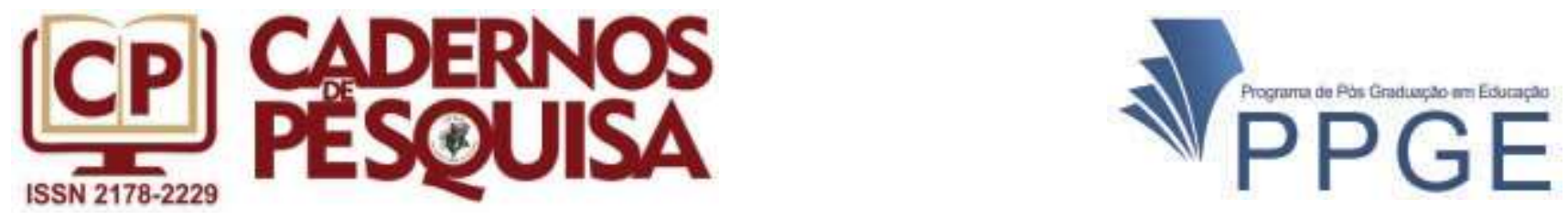

\title{
GESTÃO EDUCACIONAL E TRABALHO PEDAGÓGICO: INSTITUINTES PARA A REALIZAÇÃO DO PROJETO DE ESCOLA
}

\author{
EDUCATIONAL MANAGEMENT AND PEDAGOGICAL WORK: \\ INSTITUTING FOR THE ACHIEVEMENT OF THE SCHOOL \\ PROJECT
}

\author{
GESTIÓN EDUCATIVA Y TRABAJO PEDAGÓGICO: \\ INSTITUYENDO PARA LLEVAR A CABO EL PROYECTO \\ ESCOLAR
}

\author{
Daianny Madalena Costa ${ }^{1}$ \\ ORCID: http://orcid.org/0000-0001-7045-0259
}

Sandra Simone Höpner Pierozan ${ }^{2}$

ORCID: http://orcid.org/0000-0003-0720-8325

\begin{abstract}
Resumo: O presente artigo tem por objetivo analisar o projeto político-pedagógico - PPP, a gestão escolar e o trabalho pedagógico desenvolvido em escolas municipais de São Leopoldo, no estado do Rio Grande do Sul. Para tanto, foram realizadas entrevistas com quatro equipes gestoras a partir do projeto de cada uma das escolas, constituindo-se, assim, numa pesquisa de caráter qualitativo. As análises dos dados foram realizadas em articulação com a produção brasileira e estrangeira de pesquisas no campo da gestão e organização das escolas, enfatizando o planejamento e os elementos da gestão democrática. Em meio ao conjunto de relações e fazeres entre a equipe gestora e os professores, conclui que a falta de articulação entre o planejado e o realizado, especialmente na conexão entre o PPP e o trabalho pedagógico é ainda um dos principais entraves no cotidiano escolar que deflagram dificuldades existentes para o trabalho pedagógico.
\end{abstract}

Palavras-chave: Projeto Político-Pedagógico. Trabalho Pedagógico. Equipe Gestora e Professores. Gestão Educacional.

Abstract: This article aims to analyze the Political-Pedagogical Project - PPP, school management and the pedagogical work developed in municipal schools in São Leopoldo, in the state of Rio Grande do Sul. Therefore, four management teams were interviewed from the project of each the schools, thus constituting a qualitative research. Data analyzes were carried out in conjunction with Brazilian and foreign research production in the field of school management and organization, emphasizing planning and elements of democratic management. Amidst the set of relationships and actions between the management team and the teachers, it was concluded that the lack of articulation between what was planned and what was done, especially in the connection between the PPP and the pedagogical work, is still one of the main obstacles in the daily school life that triggers existing difficulties for pedagogical work.

\footnotetext{
${ }_{1}$ Universidade do Vale do Rio dos Sinos (UNISINOS) - São Leopoldo - RS, Brasil.

2 Universidade Federal da Fronteira Sul (UFFS) - Campus Erechim - RS, Brasil.
} 
Keywords: Political-Pedagogical Project. Pedagogical work. Management Team and Teachers. Educational management.

Resumen: Este artículo tiene como meta analizar el proyecto político-pedagógico - PPP, gestión escolar y labor pedagógico desarrollado en las escuelas municipales de São Leopoldo, en el estado de Rio Grande do Sul. Para ello, se realizaron entrevistas con cuatro equipos directivos basados en el proyecto de cada una de las escuelas, constituyendo así una investigación cualitativa. Los análisis de datos se realizaron en conjunto con la producción de investigación brasileña e extranjera en el campo de la gestión y organización escolar, enfatizando la planificación y los elementos de la gestión democrática. En medio del conjunto de relaciones y acciones entre el equipo directivo y los maestros, concluye que la falta de articulación entre el planeado y el hecho, especialmente en la conexión entre el PPP y el trabajo pedagógico sigue siendo uno de los principales obstáculos en la vida escolar diaria que desencadena las dificultades existentes para el trabajo pedagógico. Palabras-clave: Proyecto Político-Pedagógico. Trabajo Pedagógico. Equipo directivo y maestros. Gestión Educativa.

\section{INTRODUÇÃO}

A pesquisa iniciou-se em 2019 com a proposta central de identificar as articulações entre o projeto político-pedagógico (PPP), a gestão educacional e o currículo escolar. Um processo composto por leituras desses documentos e a realização de entrevistas junto às equipes gestoras de quatro escolas da rede municipal de Educação de São Leopoldo-RS. A partir disso, buscamos neste artigo, apresentar os vínculos entre o PPP e a organização do trabalho pedagógico, o qual ancora-se na possibilidade de compreender sua estreita relação com as transformações da prática pedagógica e a gestão escolar.

Decorrente de legislação que regulamenta a gestão democrática e determina a necessidade de que todas as escolas construam a sua proposta pedagógica (BRASIL, 1996), o PPP é um compromisso institucional dos sujeitos que a compõem. Essa disposição encontrada no texto legal acerca da organização da educação brasileira, mesmo passado vários anos de sua vigência, ainda merece ser estudada e refletida. São muitas as razões pelas quais podemos acreditar nessa importância. Por exemplo, as dúvidas e equívocos quanto à sua elaboração; a dificuldade de implementação de propostas possivelmente idealizadas; o modo como o documento passa a ser secundarizado ou subsumido nas escolas; a ideia de que sua existência esteja mais atrelada às questões da burocracia (a lei obriga que exista) do que propriamente para contribuir com o cotidiano da escola; a lógica de que seja possível afirmar uma ideia desvinculada de um exercício sobre sua realização - "o papel aceita tudo"; entre outras. Tais indicativos são perceptíveis em momentos de diálogos com os educadores, curso de formação, atividades de pesquisa e extensão, e, compõe a necessidade de que nos coloquemos a pensar sobre sua importância e articulação com outros elementos do fazer escolar.

Por isso, no sentido de contribuir com o debate sobre o contexto educacional e as possibilidades de impulsionar a necessidade de um projeto de escola, capaz de tornar 
evidentes os sonhos de sua comunidade e de impulsionar uma gestão coletiva para a sua elaboração/efetivação é que nos propomos a analisar quais são os objetivos educacionais estabelecidos nos PPPs, e sua relação com o contexto da gestão da escola e como dialogam com o trabalho pedagógico. Para isso, trazemos a síntese proposta por Ferreira (2018, p. 594), quando assevera que o trabalho pedagógico vai além daquilo que se efetiva em sala de aula, ou seja,

Considera-se, ainda, que a produção do conhecimento pressupõe envolvimento e participação política em todos os momentos escolares, além de intenso imbricamento, comprometimento e responsabilidade com o projeto pedagógico institucional. Trata-se, pois, de um movimento dialético entre o individual e o coletivo [...]. (grifos nossos).

$\mathrm{Na}$ perspectiva assumida por esse estudo, a análise dos PPPs das escolas e as entrevistas com os sujeitos gestores apontaram para uma gestão escolar com distribuição de responsabilidades; um processo ensino-aprendizagem que se insere numa perspectiva de formação integral - nas mais diversas dimensões do ser humano; e assumem a cidadania como fundamento da educação escolar. Além disso, no diálogo com as equipes foram observadas as dificuldades para consolidar a proposta pedagógica indicando um distanciamento entre o que se vivencia na escola e aquilo que seria desejável.

Logo, partiremos dos elementos instigadores sobre a gestão e o trabalho pedagógico, que "saltaram" aos nossos olhos nessa pesquisa. Nas entrevistas realizadas às equipes gestoras, foi manifesto a complexidade da articulação entre a gestão da escola, o trabalho pedagógico e o PPP, ou seja, a relação existente entre o que pretende o projeto de escola e como será possível uma orientação por parte dos gestores junto aos professores, para que ele se realize. Como o PPP poderá "sair" do papel - se não houver a liderança expressiva de gestores comprometidos com ele, e, considerando "seu" grupo de professores, levando em conta o trabalho pedagógico ali desenvolvido?

Para o encaminhamento dessa discussão, o texto está organizado em três seções, além desta introdutória, do contexto metodológico e das considerações finais. Na primeira parte, problematizamos a gestão educacional e a centralidade do PPP. Na segunda, apresentamos as relações entre o trabalho pedagógico e o PPP. E, na terceira, discorremos sobre os achados da pesquisa considerando a relação da gestão com as ações na escola.

\section{O CONTEXTO METODOLÓGICO}

Partimos da compreensão de que "A realidade social é a cena e o seio do dinamismo da vida individual e coletiva com toda a riqueza de significados dela transbordante" (MINAYO, 2016, p. 14). O cotidiano em que se insere as atividades escolares é, nesse sentido, carregado de uma profunda complexidade, por isso, a pesquisa em educação se ancora numa concepção entre processo-produto, a qual se realiza desde a elaboração do problema, sua manifestação, a teorização do campo e conceitos, até as diversas atividades 
e procedimentos de interação e análise. Diante disso, buscamos pela pesquisa qualitativa, as aproximações e os distanciamentos necessários, para que compreensão e interpretação sejam possíveis, na direção de reconhecer um processo "compreensivo e interpretativo contextualizado" (MINAYO, 2016, p. 21).

A pesquisa de campo nas ciências sociais, conforme Ghedin e Franco (2008) compõe-se de ações orientadas para serem realizadas em um determinado contexto, com o objetivo de compreender o objeto. O conhecimento é, então, resultante de "um determinado contexto vivido por um conjunto de sujeitos que constroem suas relações na medida que são significativas para o constructo de suas existências." (GHEDIN; FRANCO, 2008, p. 193).

A pesquisa envolveu a análise documental dos projetos político-pedagógicos, de quatro escolas da rede municipal de educação de São Leopoldo-RS, sendo aqui denominadas "A", "B", "C" e "D". A partir disso, foram organizadas diferentes entrevistas semiestruturadas para o conjunto dos gestores das respectivas escolas municipais. Os aspectos presentes nas questões ancoram-se nos eixos: administrativo-pedagógico, aspectos relacionados às concepções de gestão escolar e PPP. As entrevistas semiestruturadas, realizadas separadamente com cada equipe escolar, foram previamente agendadas e posteriormente transcritas. Contaram com a participação total de quatro diretores, quatro vice-diretores e dez supervisores das escolas.

A seleção dos sujeitos da pesquisa considerou a atuação de docentes que compõem as equipes gestoras das escolas, os quais, mediante conhecimento dos termos da pesquisa em relação aos aspectos éticos, assinaram os Termos de Consentimento Livre e Esclarecido (TCLE). O procedimento dessa modalidade de entrevista, teve o intuito de abrir novas questões durante o diálogo, sempre que necessário e se justificou porque a "[...] formulação da maioria das perguntas [é] prevista com antecedência e sua localização é provisoriamente determinada." (COLOGNESE; MÉLO, 1998, p. 144).

A partir da análise desses dados ocorreu a importância de considerar, mais profundamente, uma questão recorrente identificada nas entrevistas: o trabalho com os professores, ou ainda, as dificuldades em acompanhar e promover um trabalho pedagógico que fosse ao encontro daquilo que é proposto nos PPPs. A ideia, portanto, de realizar uma triangulação para observar a articulação entre os documentos, o trabalho pedagógico e a gestão escolar, origina-se dos achados que se elevaram nas entrevistas.

A análise dos dados foi realizada por meio da sistematização das informações, coletadas tanto nos estudos dos PPPs, quanto nas transcrições e leituras das quatro entrevistas coletivas, a elaboração de quadros de análises e o diálogo com o referencial teórico.

Escolhemos examinar de modo detalhado e associado - os projetos político-pedagógicos das escolas e as falas dos sujeitos - por considerar insuficiente somente a leitura dos documentos físicos. Observar o contexto de articulação permitiu estabelecer um diálogo com aqueles que orientam práticas na direção de um trabalho pedagógico na escola. 
Os instrumentos de coleta, portanto, demonstram nosso compromisso em busca de um processo compreensivo-interpretativo que pudesse "sustentar" as articulações entre a gestão escolar, o projeto da escola e o trabalho pedagógico. Sendo assim, partimos para uma breve descrição da estrutura escolar do município de São Leopoldo.

Localizado na região metropolitana de Porto Alegre/RS, possui 52 escolas, sendo apenas uma delas, localizada na zona rural. Nesta rede são atendidos mais de 23 mil alunos entre a educação infantil e o ensino fundamental - incluindo as modalidades de educação especial e educação de jovens e adultos (EJA). O quadro de professores chega a dois mil e cem docentes.

A escolha das equipes gestoras de cada escola acontece por eleição, em que os(as) candidatos(as) a diretor, vice-diretor e supervisores, compõem uma chapa, formando a proposta da equipe diretiva que concorre ao pleito. Votam, pais, alunos, professores e funcionários que fazem parte da escola. Os eleitos dirigem o estabelecimento escolar no período de 4 anos de atuação nas referidas funções. Nessa rede de ensino, não há concurso para supervisores e orientadores educacionais, nem há obrigatoriedade quanto à sua formação em pedagogia ou gestão escolar para as atividades realizadas pela supervisão escolar. Ou seja, o critério para pertencer à equipe diretiva é a formação em curso de licenciatura, ou ser professor.

A partir do desenho metodológico e da contextualização do cenário educacional onde se encontram as escolas que participaram dessa pesquisa, passaremos mais adiante a análise dos dados produzidos. A seguir, traremos os marcos teóricos acerca do projeto político-pedagógico, da gestão escolar e do trabalho pedagógico, como conceitos nos quais serão entrelaçados na última seção deste artigo.

\section{A GESTÃo EDUCACIONAL E A CENTRALIDADE DO PROJETO POLÍTICO-PEDA- GÓGICO NO FAZER DA ESCOLA}

Os compromissos da escola com as políticas educacionais pressupõem um amplo empenho do gestor e dos professores da instituição, focados em ações que viabilizem as condições de ensino-aprendizagem e que possam levar à melhoria da qualidade da educação básica. Por isso, um grande desafio perceptível tanto no recorte teórico apresentado, quanto a partir das falas dos gestores é manter a coesão entre o que está no papel e o que acontece na prática efetivada, e que exige um conjunto de ações, que por sua vez envolvem diversas medidas e decisões para atingir objetivos previamente acordados. As estratégias, dentro das organizações educacionais, materializam-se no projeto educativo, próprio de cada estabelecimento, com diferentes níveis de profissionalização, como evidenciado por Canário (1992), o que requer que sejam efetivados. Isso se justifica com mais afinco, quando compreendemos que, o motor da educação autoritária e desigual se alicerça sobre o distanciamento entre aquilo que afirma como ideia, daquilo que nega como prática (BRANDÃO, 1995). 
Nesse sentido, cabe destacar que a concretização de um projeto de escola, está intimamente relacionado com a existência de espaços de atuação: a sala de aula, os conselhos escolares, as reuniões internas e externas, o currículo, entre outros; os quais podem ser utilizados como meios, não únicos, nem isolados, mas que articulados com o documento que sintetiza os propósitos do estabelecimento escolar, busquem melhorar a educação pública. Evidencia-se assim, "o caráter mediador da administração, pois sua ação na escola perpassa todos os momentos do processo de realização do ensino." (PARO, 2015, p. 255, grifo nosso).

Inseridos num contexto que sugere a escola para a promoção da cidadania, como propõem a Lei de Diretrizes e Bases (LDB) (BRASIL, 1996) e os PPPs analisados, a escola necessita da presença de mediadores comprometidos com um projeto emancipatório de educação e de sociedade, bem como o acionamento de mecanismos que considerem a gestão democrática, como imprescindível para a construção e à implementação de seu projeto político-pedagógico. O atributo da mediação, pode ser desempenhado em diversos momentos e por distintos profissionais. Estes por sua vez

(...) não podem ter por parâmetro uma lógica institucional apenas baseada na racionalidade, desconhecendo que as dimensões subjetivas, a cultura, e o desejo de mudar constituem, também, forças impulsionadoras no sentido de que a escola pública brasileira realize as funções dela esperadas. (AZEVEDO, 2005, p. 38).

Para dar continuidade, portanto, à ideia de que a gestão escolar tem um papel mediador diante do projeto da escola, trazemos o quadro a seguir, onde há alguns elementos que identificamos como suas finalidades, encontrados nos PPPs estudados.

Quadro 1 - Escola e seus objetivos declarados no PPP

\begin{tabular}{|c|l|}
\hline Escolas & \multicolumn{1}{|c|}{ O que diz sobre "ser" escola } \\
\hline A & $\begin{array}{l}\text { A concepção de Escola declarada, incita a ideia da escola pública como: gratuita e } \\
\text { laica. Direito de todos e todas e dever da família e do Estado para o desenvolvimento } \\
\text { e a aprendizagem dos estudantes. Tem em suas finalidades e compromissos suprimir } \\
\text { qualquer tipo de preconceito. }\end{array}$ \\
\hline B & $\begin{array}{l}\text { Acesso ao conhecimento de qualidade, considerando a intenção de formar cidadãos } \\
\text { conscientes de seus direitos e deveres. É tarefa da escola, democrática, plural e inclu- } \\
\text { siva desenvolver a capacidade do indivíduo em conhecer a si próprio, compreender os } \\
\text { imensos problemas de desigualdade social, econômica e cultural, de valores, de finali- } \\
\text { dades; e frente a isso possam ao mesmo tempo apropriarem-se da riqueza civilizatória } \\
\text { já produzida e combater os problemas existentes. Por fim, a escola é entendida como } \\
\text { uma instituição capaz de agir coletivamente, integrando-se à sua comunidade. }\end{array}$ \\
\hline C & $\begin{array}{l}\text { A escola é pensada como espaço de acolhida, escuta e diálogo. Tem como papel fun- } \\
\text { damental a formação integral dos educandos em que a construção do conhecimento e } \\
\text { o processo de socialização caminham juntos. }\end{array}$ \\
\hline D & $\begin{array}{l}\text { O compromisso fundamental da escola é garantir o acesso, a permanência e a apren- } \\
\text { dizagem de todos os estudantes na perspectiva de sua formação integral e por meio de } \\
\text { uma Educação Integral (de tempos e espaços de um justo e digno viver). }\end{array}$ \\
\hline
\end{tabular}

Fonte: Elaborado pelas autoras. 
Ao identificarmos o caráter formativo, do ponto de vista ético, social e intelectual, do qual a escola lança-se e compromete-se, está manifesto seu caráter para além das aprendizagens conteudistas. Os tempos e momentos da gestão, articulados aos objetivos que a mesma se propõe, carecem, em nosso entendimento, de suportes diferentes. A gestão democrática não será alcançada em meio a expressões autoritárias e burocráticas, o que em outro momento histórico até foi aceito, mas não cabe no espaço da gestão que se propõe participativa e democrática.

À vista disso, além de estar claro, que o objeto a ser compreendido pela gestão, é a escola, seu sentido e objetivos - declarados em seu PPP, para processos de ensino-aprendizagem que gerem qualidade educacional e cidadania, será necessário que cada equipe gestora, junto aos docentes, busque diferentes meios de atuação para a promoção deles. A propósito, para que a organização e a gestão da escola se efetivem, são acionadas ações específicas que perpassam o planejar, organizar, dirigir e avaliar. A condução destas ações, as formas de organização e gestão, nas palavras de Libâneo (2008, p. 294), "[...] são sempre meios, nunca fins, embora, muitas vezes, erradamente, se tratem meios como fins: os meios existem para se alcançarem determinados fins e lhes são subordinados".

Atender aquilo que não era prática em momento anterior é um dos componentes da inovação, que permite fazer uma ou mais ações de modo renovado. Se, então, os gestores buscam criar oportunidades de que ensino e aprendizagem sejam processos que desenvolvam os objetivos pretendidos no PPP, para isso haverá novos meios, possivelmente mais participativos e democráticos, pois não há exercício de busca de mudanças quando se colocam limites a esses elementos.

Para Carbonell (2002) as mudanças inovadoras partem das escolas, de seus profissionais engajados, existentes em todos os níveis do ensino. Serão inovadoras, se concentrarem esforços, mais no processo do que no resultado. Mas para isso é preciso tempo e persistência. Determinação e um trabalho articulado entre todos os membros da escola, que de modo prospectivo busquem idealizar novas concepções e organização do conhecimento escolar. Sendo assim, a inovação aqui destacada é pedagógica, pois perpassa concepção e organização do contexto escolar, dialoga com os modos de ensinar e aprender, com currículo e propostas educativas.

Ademais, vivenciar uma gestão democrática como propõe os princípios legais da educação pública no território brasileiro (BRASIL, 1996), significa, efetivamente, interrogar sobre - como se faz essa ação conjuntamente. Como construir coletivamente os meios para a promoção da cidadania e do sujeito "integral"? - como manifestam os PPPs analisados. Essa, sem dúvida, é uma ação que requer o envolvimento de todos os que estão diretamente implicados no cotidiano da escola, nas diversas e múltiplas funções que nele ocorrem. E nesse sentido, é fundamental contarmos com o envolvimento de todos e para tal, aprofundar a participação dos professores. 
Do contrário, corre-se o risco de agravar o entendimento sobre o que seria a gestão da escola. Se é compreendida como a relação restrita aos aspectos de uma racionalidade, compreendidos muitas vezes como administrativos, numa visão mais tradicional e gerencial, ou seja, àquilo que se limita "às normas e aos procedimentos relativos à organização e ao funcionamento da escola" (PARO, 2015, p. 20, grifo nosso), deixando de lado os vínculos com o que é pedagógico. Então, ao mesmo tempo que concentra essa atividade na figura do diretor, tira-lhe a responsabilidade pedagógica propriamente dita, excluindo dessa liderança, a preocupação com tais aspectos da escola.

Por isso, em se tratando da gestão da escola é relevante um entendimento coletivo acerca de seu objeto e seu para quê. Afinal, à instituição escolar, não basta sua normatização, ou um projeto político-pedagógico que esteja aprovado por uma mantenedora ou um conselho municipal de educação. Não se fará, única e exclusivamente porque há algo que esteja ali evidenciado. O estabelecimento escolar para se realizar em sua perspectiva, dependerá da ação organizada, do trabalho daqueles que Ihe são afetos. Inclusive, a própria ideia à qual se filia. Como fruto de um adensamento epistemológico, filosófico e de trabalho reflexivo que lhe dê potência.

Nesse sentido ressaltamos, conforme Russo (2011, p. 498), que

As práticas escolares são práticas sociais historicamente construídas no âmbito das formas concretas, que, em diferentes períodos históricos, dão materialidade à instituição, ou seja, são práticas organizacionais que visam contribuir com os fins educacionais e escolares, construídas a partir da cultura escolar ou das formas que a escola assume ao longo do tempo.

Por outro lado, nas entrevistas realizadas, as equipes apontam preocupações com a desmotivação de parte dos professores, especialmente no sentido de comprometerem-se com a escolha de metodologias mais inovadoras de ensino e aprendizagem. Os relatos evidenciam que um conjunto de docentes não se desprende das concepções e do fazer mais tradicional do ensino. Este ponto é de fato uma grande preocupação. Se defendemos a escola democrática, participativa e autônoma com foco na qualidade da educação, como isso de fato se efetivará sem que o projeto tenha adesão de todos? Noutras palavras, perguntamo-nos se há como separar a elaboração de um projeto de escola, daquilo que efetivamente se quer ver acontecer dentro dela. Como diz Freire (2002, p. 27), é inadmissível separar prática de teoria, posto que "o meu discurso sobre a teoria deve ser o exemplo concreto, prático, da teoria. Sua encarnação".

A práxis, portanto, identifica para a escola, que é possível examinar a si e a realidade social onde está inserida e, diante das constatações, imprescindível planejar o futuro, pensar, propor, agir e avaliar, num processo sucessivo. Afinal, o estabelecimento escolar ao mesmo tempo que está inserido numa sociedade, organizar-se-á para contribuir em relação a ela (TARDIF; LESSARD, 2011). Diante dos problemas apresentados, essa contribuição 
poderá ser de fortalecimentos, continuidades ou superações. Dentro dessa percepção, professores e equipes gestoras podem criar as condições para que a proposta pedagógica seja organizada com base em conhecimentos diversos em um ambiente humano e humanizador para uma sociedade que pretendem colaborar, que valorize a experiência, sem preconceitos, ou quaisquer modos de discriminação, para a formação da cidadania.

É nesse sentido que alertamos para a condição de que os gestores da escola, mesmo com funções e atribuições distintas, validem e legitimem a participação coletiva, o planejamento e o respeito aos contratos estabelecidos a partir de um planejamento participativo. Pois, pretendemos enfatizar “(...) que devemos analisar e compreender a organização do trabalho pedagógico, no sentido de se gestar uma nova organização que reduza os efeitos de sua divisão do trabalho" (VEIGA, 2013, p. 22). Para isso, a próxima sessão irá argumentar sobre como se engendra o trabalho pedagógico na relação com o projeto da escola.

\section{INDICATIVOS DO TRABALHO PEDAGÓGICO E SUA RELAÇÃO COM O PROJETO DE ESCOLA}

Decorre dessa reflexão, o objetivo de compreender o trabalho pedagógico a partir do projeto de escola, o que requer também compreender sua natureza e quem são seus atores/sujeitos. A escola é um espaço em que todos os profissionais que nela atuam desempenham um trabalho educativo, pois as ações são organizadas com requerida intencionalidade. Porém, nesse texto pontuamos o trabalho pedagógico como aquele desenvolvido na articulação entre a gestão do estabelecimento escolar e os docentes, a partir das propostas encontradas no projeto de escola.

Os PPPs, portanto, são compreendidos como documentos escolares que guardam a possibilidade de se constituírem em instrumentos favoráveis à organização da unidade escolar, no sentido de lançar as reflexões sobre os problemas deflagrados no contexto escolar. Diante de sua elaboração estão as bases para um planejamento, que levará em conta, suas aspirações e possíveis superações. Para isso, Costa (2021, p. 221-222) reconhece sua importância, porque por seu intermédio a escola pode

[...] se pôr a avaliar sobre a realidade que tem, declarando suas necessidades, suas concepções, seus rumos e seus percursos para viabilizá-lo. Sendo, nesse sentido uma parte da organização escolar e seu planejamento. Para isso, sua construção requer responder, mesmo que provisoriamente, as ideias que os sujeitos da vida escolar têm sobre o tempo em que vivem, sobre a sociedade onde se encontram. O que querem ajudar a formar e, para realizá-lo, quais intenções manifestam, como pretendem alcançá-las e o que farão para isso.

Reconhecemos, nesse primeiro momento, portanto, que o planejamento significa "um processo científico de intervenção na realidade" (GANDIN; GANDIN, 2011, p. 21) e 
compõe parte do trabalho pedagógico. É um ato intencional, que exprime um sentido explícito de compromisso, pois intervir na realidade de uma escola é algo que perpassa pelas relações e práticas exercidas por meio da reflexão conjunta e do compromisso daqueles que a constituem.

Como propõe Gadotti (2000), numa conversa com Freire e Guimarães, um planejamento central não significa a inexistência de participação, pelo contrário, poderá ser o desaguadouro dela. Porém, quando não desenvolvido, leva ao descrédito. É por isso, que (GANDIN; GANDIN, 2011, p. 22) afirma que

Os profissionais das escolas perderam quase por completo a noção da relação ação/ resultado (provavelmente isto é só consequência); com isso as ações escolares passaram a ser realizadas como fins em si mesmas e todo fracasso, além de não compreendido, transferiu-se para a responsabilidade dos alunos, de seus pais ou da sociedade.

O projeto de escola, seu planejamento, como trabalho pedagógico, reitera a importância das decisões coletivas, reconhecendo a relação entre os fins e os meios da prática educativa. Por isso, vai de encontro aos fazeres individualistas e competitivos que podem ser identificados na escola, (LÜCK, 2014) nas suas relações internas (entre servidores e estudantes) e externas (com sua mantenedora e comunidade).

Thurler (2001) enfatiza que "O individualismo permanece no âmago da identidade profissional” (p. 59) docente. Isso, obviamente, traz uma incontestável dificuldade para exercermos uma proposta coletivizada. Então, como construí-la para a promoção da cidadania e do sujeito integral? Essa, sem dúvida, é uma ação que requer o envolvimento de todos os que estão diretamente implicados com o cotidiano da escola.

A construção de que estamos falando, reconhece como imprescindível um trabalho pedagógico que promove e articula reflexão e ação, ambas originadas na perspectiva de um planejamento compromissado com a educação/escola/projeto. Como nos brindou Freire (1979, p. 16), "a primeira condição para que um ser possa assumir um ato comprometido está em ser capaz de agir e refletir". Dessa maneira, enfatizamos uma gestão capaz de produzir um novo fazer, que alimente as relações cotidianas no interior do estabelecimento escolar, de forma coletiva e participativa para o exercício comprometido com as finalidades propostas no projeto de escola.

Outra questão acrescentada, é que ao retirar do ato pedagógico, os fins a que ele se destina, deixando meramente a transmissão de conteúdos, a condição do trabalho é subsumida. Isso porque, "a própria educação deve ser entendida como trabalho, uma vez que supõe uma atividade e um fim a ser perseguido" (PARO, 2011, p. 90).

Mas, se o PPP já apresenta uma proposta de trabalho, a partir dos fins estabelecidos, por que ela não seria desenvolvida? Alguns autores já buscaram responder essa questão. Veiga (2013) retrata os documentos que ficam engavetados, que servem apenas para comprovação burocrática. Vasconcellos (2006) destaca que os docentes podem participar das discussões do projeto político-pedagógico sem, no entanto, haver envolvimento com o 
projeto em si. E, Lück (2014), expressa que a realização de ações episódicas, sem a visão do todo, prejudica a execução de uma proposta. O projeto político-pedagógico visto apenas como um mero documento, uma formalidade burocrática, atrelado à descrença no planejamento são alguns dos fatores que podem justificar o não desenvolvimento de um trabalho pedagógico que articule o plano de trabalho do docente com a proposta da escola e a ação dos gestores escolares para essa articulação, assim como uma possível dissociação da proposta em relação à realidade escolar.

Para além de um documento que respalda a existência e funcionamento da instituição de ensino, a maior contribuição do PPP para o ambiente educacional está no âmbito da práxis, da reflexão-ação. Como possível instrumento de mobilização, pois evidencia uma forma de contrapor-se aos fazeres fragmentados e sua rotinização. Diante disso, compreendemos que seja possível seguirmos refletindo na direção de como a gestão da educação poderá contribuir na articulação do trabalho pedagógico para levar a efeito o projeto de escola ao qual está correspondida.

\section{"NÃO TÁ BOM AINDA": DIÁLOGO ENTRE O PPP, A GESTÃO E O TRABALHO PE- DAGÓGICO}

Nesse ponto, à luz dos elementos trazidos anteriormente, desenvolvemos uma conexão a partir da fala dos gestores escolares entrevistados, no sentido de oferecer um diálogo desde a elaboração e implementação de um PPP à relação com o trabalho pedagógico. Vale destacar que as entrevistas foram realizadas coletivamente, com os membros das equipes de cada unidade escolar e após transcritas e analisadas - na relação com o estudo dos PPPs e do referencial teórico que fundamenta nosso movimento interpretativo. Para isso,

[...] quando falamos de análise e interpretação de informações geradas no campo da pesquisa qualitativa, estamos falando em um momento em que o pesquisador procura finalizar o seu trabalho, ancorando-se em todo o material coletado e articulando esse material aos propósitos da pesquisa e à sua fundamentação teórica. (GOMES, 2016, p. 73).

Verificamos que uma das situações que afligem os gestores e que foi apresentada em todas as entrevistas é a dificuldade na aproximação e convergência das ações dos docentes em relação ao que dispõe o PPP. Acreditamos que a atuação dos gestores focada nas oportunidades de um planejamento formativo, como parte do trabalho pedagógico, pode se revelar como aspecto agregador, no sentido de aproximar professores e a gestão escolar para melhor conhecimento dos objetivos e metas da escola, de sua estrutura organizacional e dinâmica, bem como, propiciar um clima de trabalho mais favorável para a implementação do projeto da escola. 
Sendo assim, partimos da figura a seguir, onde há uma breve caracterização dos diversos segmentos internos da escola, que compõem seu cotidiano. Alunos, professores, funcionários e equipe gestora relacionam-se entre si, têm suas especificidades como grupo que formam e, ao mesmo tempo, suas próprias subjetividades, como sujeitos, que estão juntos num mesmo espaço, formando o que aqui estamos chamando de - segmento. É, portanto, crível que isso revele boa parte das complexidades que se estabelecem numa unidade escolar. Isso sem contar com o contexto externo em que se insere. Na figura abaixo temos uma síntese dos vários segmentos envolvidos no cotidiano escolar e sua(s) relação(ões).

Figura 1 - Os atores do processo educativo e suas relações
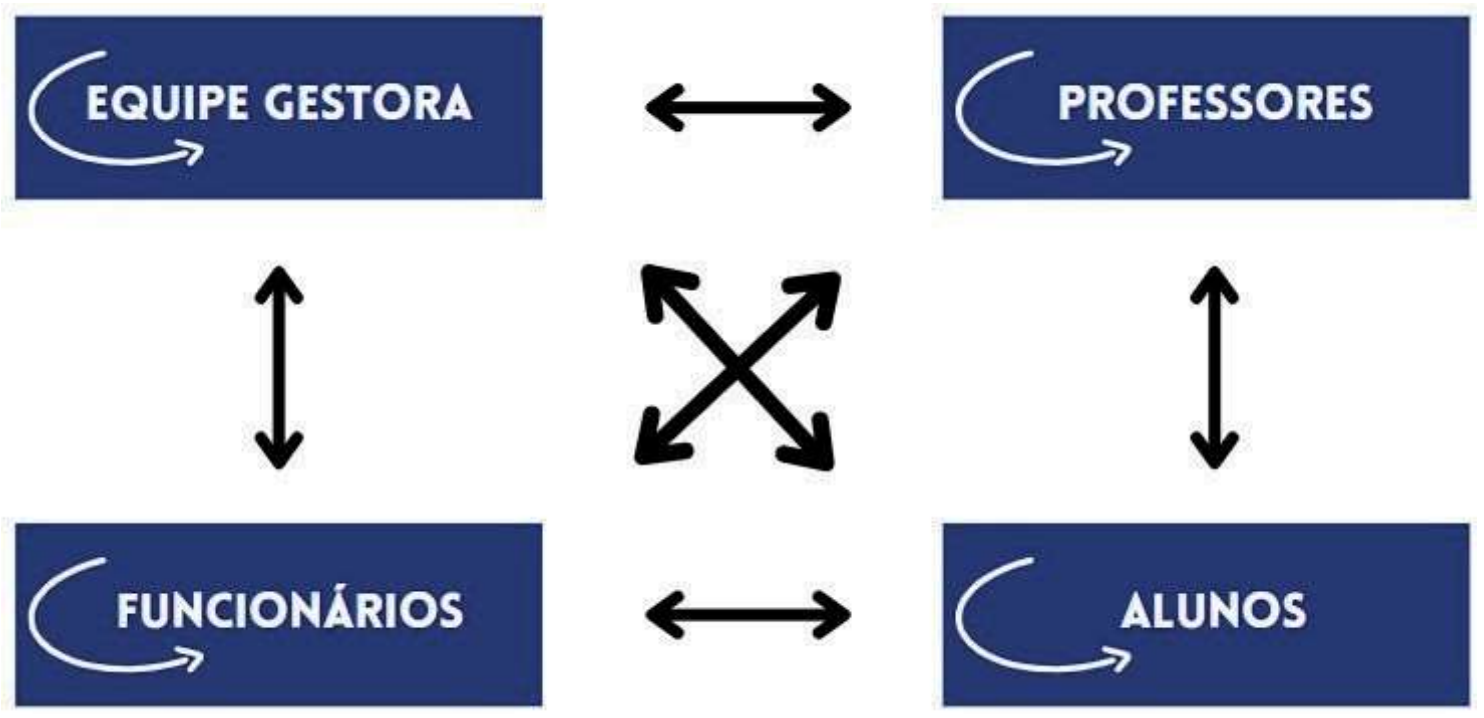

Fonte: Elaborado pelas autoras.

Ao concebermos, portanto, o trabalho pedagógico, que "por sua natureza, está relacionado ao como os grupos que compõe a escola se organizam, como entendem e produzem educação" (FERREIRA, 2018, p. 595), propomos para esse texto a centralidade da análise entre a equipe gestora na relação com os professores das mesmas unidades escolares. Portanto, o trabalho pedagógico se realiza, invariavelmente, entre esses sujeitos, seus grupos e seus relacionamentos. Sobre isso, Tardif e Lessard (2011, p. 20) declaram que "(...) as relações entre os trabalhadores e as pessoas constituem o processo de trabalho, o qual consiste em manter, mudar ou melhorar a situação humana (...)". Sendo assim, ao compreendermos os procedimentos e movimentos existentes no interior da escola, especificamente entre as ações de apoio, acompanhamento, impulsionamento, influência, liderança dos gestores para com os professores, na direção da realização do PPP, manifestamos nossa percepção quanto à responsabilidade daqueles sobre isso. 
A reflexão assume, por isso, o papel de colocarmo-nos na condição de analisar como essa articulação ocorre, compreendendo o quanto a equipe gestora encontra-se envolvida e implicada nas definições contidas no PPP e a relação com os professores - no desenho do trabalho pedagógico.

Ao considerarmos esse conjunto de ideias, não podemos nos furtar em considerar a depreciação e o descrédito, que muitas vezes ocorre sobre o projeto político-pedagógico, o qual se reflete sob várias e inúmeras razões, que inviabilizam seu sentido no contexto escolar. Em última instância, o rompimento com a ideia de que esse documento possa auxiliar os gestores no seu papel de direção e de coordenação. Por isso, no conjunto observado, algumas ideias preponderavam: a não utilização do PPP como base para o planejamento dos professores; a naturalização das práticas tradicionais/conservadoras; a dificuldade de estabelecer consensos entre os docentes - sobre aspectos como currículo, avaliação, exigências de aprendizagem etc - pretendidos no documento; o modo como os PPPs são construídos, e a sua temporalidade/validade. Essas caracterizações, na maioria das vezes, não estão desarticuladas, ou desconectadas. De todo modo, parecem encontrar acordo numa mesma raiz, difusa e contraditória.

De um lado, o PPP relaciona-se a uma ideia utilitarista, em que elaborá-lo corresponde a uma racionalidade técnica, à norma burocrática. Nesse sentido, vira um documento enfadonho que não tem significado para a escola, seus sonhos e destinos. $E$, contrariamente ao pressuposto de ser um incentivador de uma possibilidade de mudanças, autonomia, reflexão sobre a função da escola e sua qualidade, investe numa estrutura baseada na compartimentalização e na prática individualizada evidenciando uma investida à necessidade de reorientação para uma unidade de objetivos que direcione e coordene à diversidade da ação docente.

Essa argumentação ainda, tende a demonstrar a fragilidade na compreensão epistemológica sobre as concepções que se descreverão no documento, pois no documento há uma compreensão de mundo, de homem de sociedade e de educação, sendo estabelecidos um conjunto de consensos dentro desses limites teórico-metodológicos. Contudo, se, quando lido pelos integrantes da escola, não houver sentido, ou ficar a impressão de que se trata de uma "colcha de retalhos" está claro que foi realizado por algumas pessoas, ou foi escrito para "agradar" a alguém externo à escola, dado que não se reconhecem nele. Perspectivados sobre esse paradigma, a equipe da escola $A$, propõe que

"[...] quando foi fundamentado a parte teórica ali que a gente acaba colocando e que a gente coloca a visão de aluno, de pais, de professores né que tu vai colocando ali, da juventude, a gente coloca mais de uma forma, porque não é a forma que eu penso né, então a gente coloca ali, só que na hora de falar que a prática do professor numa escola, ela segue vários, várias linhas." 
Noutras palavras, no caso de não acreditar na condição de mudança da escola, esse documento não passa de uma proposta vazia e sem sentido, portanto, pode ter um texto "bonito", teoricamente inovador, rebuscado e que responde a novos fazeres, mas já se origina desacreditado. E sobre isso a equipe da escola $A$ continua afirmando que muitas vezes o texto do PPP é um amontoado de palavras e jargões altamente progressistas, mas na hora de praticá-lo, nem entendem o que efetivamente está a propor (Entrevista com a equipe gestora da escola $A$ ).

No sentido oposto, ao acreditarem na lógica que o PPP institui - de que expressa os sonhos da escola e, a partir disso poderiam se pôr a agir; os gestores expressam as dificuldades encontradas em liderar os processos de gestão do trabalho pedagógico, ou seja, de sua atribuição em instigar, sugerir, acompanhar, apoiar, contribuir com a promoção para que os professores possam se responsabilizar e se comprometer com o projeto da escola. Quem sabe, modificando a didática e a metodologia em sala de aula, refletindo sobre suas práticas, discutindo sobre a função da escola, analisando os fazeres escolares, integrado as diversas ações existentes no ambiente escolar, para concretizar os fins estabelecidos no PPP e, que grosso modo, anunciamos no Quadro 1. Logo, tomamos a centralidade da relação entre a gestão e a docência "como" e "para o" trabalho pedagógico.

Essa relação é evidenciada por Libâneo (2008, p. 263), quando considera que

[...] a principal razão para que as escolas sejam mais bem organizadas e administradas é a melhoria da qualidade das aprendizagens escolares dos alunos. Ou seja, uma escola bem organizada e gerida é aquela que cria e assegura as melhores condições organizacionais, operacionais e pedagógico-didáticas de desempenho profissional dos professores, de modo que seus alunos tenham efetivas possibilidades de serem bem sucedidos em suas aprendizagens.

Os profissionais das equipes diretivas assumem o papel de gestar, coordenar o trabalho pedagógico, coletivamente, impulsionando e favorecendo as condições de sua realização. No entendimento de Libâneo, Oliveira e Toschi (2012, p. 476), diretores e coordenadores

[...] precisam reconhecer que sua ocupação tem uma característica genuinamente interativa, ou seja, está a serviço das pessoas e da organização, requerendo uma formação específica a fim de buscar soluções para os problemas, saber coordenar o trabalho conjunto, discutir e avaliar a prática, assessorar os professores e prestar-lhes apoio logístico na sala de aula.

Desse modo, elencamos o planejamento como um aspecto que parece ajudar a sustentar a reflexão entre o PPP e o trabalho pedagógico. E para promover um debate indispensável acerca das questões que circulam nos ambientes educacionais, é preciso garantir 
no calendário escolar uma quantidade de encontros sem os quais não será possível um agir organizado e muito menos um planejamento virtuoso.

E já pensando sobre a relação entre momentos de discussão e planejamento, entendemos que este deva ser realizado de forma coletiva - propondo inclusive um diálogo acerca dos principais problemas encontrados, como por exemplo, como será a reorganização do PPP e sua implementação, o que terão a fazer e quais os investimentos diretos na escola, compondo o trabalho pedagógico. Como ilustração a esse conjunto de coisas, no sentido de dialogar acerca da necessidade de um planejamento integrado, em favor das escolas, que muitas vezes são "atropeladas" pela agenda imposta pelo órgão hierarquicamente superior, oferecemos o exemplo que segue:

"[...] um assunto que precisava ser trabalhado, uma formação pra professores e a gente ter que fazer no outro ano, que aí vieram outras demandas, a secretaria planeja as reuniões deles, esse ano principalmente planejou as reuniões deles antes de acontecer a nossa formação. As nossas reuniões tiveram que pautar nessa questão do PPP, então esse ano combinou, mas às vezes não combina (não dá certo, as datas se "acavalam")". Se tem planejado, como vai fazer?" (Entrevista com a equipe gestora da escola $\mathrm{A}$, grifos nossos).

Nesse caso, a equipe da escola A está expondo o quanto se sente desconsiderada a respeito de sua organização, seu fazer, seu planejamento, seu PPP. Não há dúvidas de que a escola possui um vínculo com o calendário de atividades da mantenedora (a secretaria de educação), porém, isso não significa que deva ser subsumida diante daquele órgão.

Ao escrever o texto: Para uma análise das instituições escolares, Nóvoa (1992, p. 20) evidencia que "a escola é encarada como uma instituição dotada de autonomia relativa, como um território intermédio de decisão no domínio educativo". Parte da dificuldade manifestada pelos gestores encontra guarida nessa afirmação. Se por um lado, espera-se que a escola se organize e desenvolva seu trabalho de modo a atender à sua realidade e comunidade; por outro, parece não haver respeito com seu planejamento, exigindo dela, o cumprimento de normas e valores do sistema, sem uma efetiva participação e reconhecimento. $O$ descompasso impacta na comunicação e no planejamento da escola que poderão dificultar o trabalho pedagógico, denominado por Tardiff e Lessard (2011) de interativo, que para o presente estudo trata da inter-relação entre professores e a equipe gestora.

Um exemplo trazido pela equipe gestora da escola A foi a reflexão em torno da reprovação. Foi a partir do reconhecimento dela como um problema a ser refletido, que a questão passou a ser enfrentada, inserindo-se como um tema a ser debatido e superado. Foi possível a produção de diálogos e iniciativas que convergiram na reestruturação do PPP, tendo como focos prioritários o currículo, a avaliação e, tangencialmente, o planejamento para a concretude de uma nova postura pedagógica diante do problema. 
Neste mesmo sentido, entendemos a relação entre o planejamento coletivo - que disporá sobre o detalhamento das ações, os responsáveis, os prazos - que serão organizados para a realização do projeto de escola e, também, sobre o último item apontado: a formação permanente. Sobre isso entendemos a importância de existir um diálogo dentro da própria escola havendo, portanto, o deslocamento de lógicas tradicionais, que possam romper com os modelos da educação bancária (FREIRE, 1987), ou sua implementação no âmbito educativo. Claro está a justificativa de existência de uma proposta formativa, que possa levar em conta essas questões. Assim, a equipe da escola B, compartilha algumas preocupações, quando questionada sobre a relação entre o currículo e as proposições encontradas em seu PPP, dizendo que esse

"[...]é um motivo de discordância entre o grupo de professores, porque existe um grupo de professores que entende que o melhor currículo para o nosso contexto, seria um currículo mais conservador, um currículo que exigisse questões mais formais, escolares, que a gente tem que priorizar a disciplina, [...] que os alunos têm que respeitar, que os alunos não respeitam. Então, tem essa coisa assim, bem forte ainda por um grande grupo, e que no momento, os profes vão exigir essa disciplina muitas vezes de uma forma que a equipe não considera a mais adequada, então tem bastante esse discurso na escola que os alunos são indisciplinados e quando a gente tem um movimento pra fazer uma pesquisa, pra fazer um trabalho, por que os alunos tão na rua? Por que os alunos tão fazendo barulho? Tão atrapalhando a minha aula, então ainda tem essa coisa bem conservadora." (Entrevista com a equipe da escola B).

Se a escola vive a contraposição entre modelos tradicionais e a possibilidade de suplantá-los, e o PPP indica uma concepção mais progressista, conforme o quadro 1 (escola B) - que considera a função da escola na formação cidadã dos alunos, por meio do conhecimento das questões relativas ao modelo econômico e social degradante que produz a desigualdade - obviamente, formações precisam ocorrer, para refletir o que acontece e viabilizar mudanças no sentido das reflexões sobre as práticas instituídas (IMBERNÓN, 2011) e quiçá suas superações. Isso porque

\footnotetext{
O contexto em que trabalha o magistério tornou-se complexo e diversificado. Hoje, a profissão já não é transmissão de um conhecimento acadêmico ou a transformação do conhecimento comum do aluno em um conhecimento acadêmico. A profissão exerce outras funções: motivação, luta contra a exclusão social, participação, animação de grupos, relações com estruturas sociais, com a comunidade... (formar cidadãos, conhecer a si). E é claro que tudo isso requer uma nova formação: inicial e permanente. (IMBERNÓN, 2011. p. 14, acréscimos nossos).
}

Pensar nessa formação, principalmente a continuada, também faz parte do planejamento; contudo, seria imprescindível concebê-la a partir da docência e não unicamente por 
aqueles que julgam-se sabedores do que os professores necessitam, sem efetivação de um diálogo sobre os temas, suas concepções e entendimentos. Ou seja, a equipe gestora ou os assessores da sede da secretaria de educação, que, geralmente, são os responsáveis por sua efetivação, quando a constroem sem levar em conta o que os professores compreendem como dificuldades ou o que concebem sobre a questão, estão colaborando com esse modelo que desarticula prática e teoria. Nosso propósito, ao trazer esses elementos, é defender a imprescindível participação dos professores sobre sua formação, sobre seus (não)saberes.

Esse é um indicativo de concepções e culturas instituídas na lógica educativa, ou seja, os diversos mecanismos de perpetuação de padrões que parecem insuperáveis e impossíveis de reinvenção, como é o caso do currículo, da sala de aula, da própria formação docente são, nesse tipo de construção acerca do trabalho pedagógico, revigorados e estimulados. Diante disso, o PPP poderá ser uma possibilidade de transformação, pois carrega uma dupla condição ao considerar

[...] o já instituído (legislação, currículos, conteúdos, métodos, formas organizativas da escola e outros), mas tem também algo de instituinte. O grupo de profissionais da escola pode criar, reinventar a instituição, os objetivos e as metas mais compatíveis com os interesses dela e da comunidade. (LIBÂNEO; OLIVEIRA; TOSCHI, 2012, p. 487, grifos dos autores)

Assim, ao mesmo tempo que o projeto institui, estabelece, cria objetivos, indica procedimentos, apresenta instrumentos, prospecta modos de agir, formas de ação, registra estruturas, diagnostica hábitos e valores - ele também, necessita ser avaliado para que se tomem novas decisões, se reavalie a orientação tomada, se corrijam desvios, realizando avaliações e modificações permanentemente, não esperando apenas o fechamento de um ciclo para fazê-lo. Contudo, há uma percepção de incompreensão, desconexão, incompletude e falta de diálogo, conforme visualizamos no depoimento a seguir:

"Eu vou te dizer assim, que eu tenho uma sensação desconfortável com essa cobrança de terminar o PPP. Fazer as correções e entregar. Algo que vai ficar vigente por três anos, porque eu não consigo enxergar que o PPP consiga durante três anos representar o mesmo grupo, as mesmas coisas, que em três anos muita coisa muda, muda a gestão da escola, mudam os professores, mudam os alunos. Eu tenho uma inquietação que um PPP que vai ficar pronto agora, parece que não dá certo, mas a gente não tem tido nos últimos anos um PPP finalizado, a gente tem tido esse processo, não era isso ainda, aí a gente olha de novo, tá, mas ainda não ficou bom, a gente tem remado em torno disso, não tá bom ainda, e agora a gente foi obrigado a dizer: é assim e assim, tem que tá bom. Eu ainda não tô sabendo lidar muito bem com isso. É o que tá posto, mas de fato a gente nas últimas versões tem algum ponto, tinha o que melhorar ou que reescrever, completo, pronto, ele nunca esteve." (Entrevista com a equipe da escola C). 
É possível perceber nesse depoimento algumas questões, entre elas elencamos duas. A primeira destaca a ideia expressa na frase: "Eu ainda não tô sabendo lidar muito bem com isso." (Equipe escola C). Imaginamos o quanto essa construção frasal poderia estabelecer um debate formativo entre equipes, segmentos escolares e a própria mantenedora, pois o quê, em se tratando de um projeto de escola, teria como princípios, como parte daquilo que se quer, identifica seu existir, está pretendendo? Por que, para a equipe da escola $C$, um PPP não pode viger por três anos? O que não pode? O que significa estar pronto? E, nunca estar? Isso significa que os gestores precisam participar de uma ampla discussão sobre o PPP, perceberem o cenário educacional e debatê-lo, investigá-lo.

A segunda questão, portanto, refere-se a ideia de "incompletude", presente nesta mesma fala. Por vezes é demonstrada bem mais no âmbito da esfera administrativa - burocrática, do cumprimento de uma norma, não haver modificações no documento nos próximos três anos. Assim complementa:

"Até mesmo porque o PPP não tem que ser uma coisa fechada tem que ser flexível às necessidades da escola, da comunidade escolar, e no momento em que o fechamos por três anos é como se não houvesse mudanças durante esses três anos, então a gente fica bem preocupado com essa questão dos três anos, mas como é algo que nós temos que cumprir." (Entrevista com a equipe da escola $\mathrm{C}$ ).

Quando dizemos que um projeto é inconcluso, estamos partindo de uma compreensão que as escolas são espaços marcados pela interação entre pessoas, pelo estabelecimento de intencionalidades, pelas conexões entre o espaço e os fazeres internos e externos. Há constantes alterações no seu constructo, as escolas e os projetos são, pois, construídas e reconstruídas socialmente, ao longo do tempo. Isso, de alguma forma, responde a própria intervenção realizada inicialmente, quando havia o estranhamento diante do "término" da elaboração do PPP, ou seja, ter concluído sua escrita, para a "aprovação" do órgão hierarquicamente superior, não significa que não poderá conter revisões. Mas contrário a isso, por ser um projeto de escola, contará com objetivos que deverão impulsionar novos instituintes, por isso, tenderá a se propagar no tempo. Parece oportuno, que a partir dessas reflexões, os sujeitos do cotidiano escolar tenham clareza sobre quais princípios a educação se pautará. Isso nos parece fazer parte dos itens inegociáveis para o período de sua vigência.

A equipe da escola C continua afirmando que o PPP favorece ao planejamento e à compreensão da escola inteira, havendo uma compatibilidade entre o trabalho realizado em sala de aula como incentivador e correlacionado ao da gestão. Então o trabalho da equipe gestora é assim descrito:

"Eu acho que tem que ser na mesma linha do planejamento do professor porque na verdade o que que eu faço todos os anos, eu recebo a minha turma, eu conheço a minha turma, eu faço uma avaliação daquela turma, e em cima disso eu planejo 
meu trabalho de um ano, é isso que a gente cobra dos profes, então eu imagino que a escola tem que pensar naquele grupo de profes e alunos daquele ano, posto o que se pretende fazer, o que se consegue fazer e onde se quer chegar dentro de uma realidade. Que só pensar em utopias não faz planejar de fato a ação [...]" (Entrevista com a equipe da escola C).

A fala é elucidativa ao manifestar a relação almejada entre o planejamento do docente tendo como referência os alunos e um ambiente que é o da aprendizagem, dando concretude para o que é projetado, do que se quer alcançar, no âmbito da turma, da escola e seu projeto. Do mesmo modo há de ser o trabalho dos gestores. E, quando manifesta que "só pensar utopias não faz de fato a ação", tende a expressar um entendimento de que pode haver um momento para as utopias, para os sonhos, mas que igualmente deverá haver o tempo para a ação. Nesse sentido, tal perspectiva contribui para a compreensão de que o PPP é um instrumento político, por isso, encontra-se intimamente articulado ao compromisso sociopolítico com os interesses reais e coletivos da comunidade escolar (VEIGA e REZENDE, 2013). Sendo assim, os interesses seriam os "sonhos", aquilo que ainda não está "concretizado", e, por isso, impulsiona o agir.

O PPP como vimos, é político, no sentido de compromisso com a formação do cidadão para um tipo de sociedade. A dimensão pedagógica reside na possibilidade da efetivação da intencionalidade da escola, que é a formação do cidadão crítico, criativo, participativo, responsável - encontrado no quadro 1.

Se, contrariamente, a compreensão do que seja político, pudesse estar associada exclusivamente ao caráter utópico do PPP, a equipe continua argumentando:

"[...] eu enxergo que o PPP na verdade deveria ser plano de ação/trabalho, o que nós queremos, como nós queremos para este ano, 2019 nós enxergamos assim e vamos fazer assim, até porque isso nos dá a chance de reavaliar pra 2020 o que não foi bacana em 2019, então nós vamos decidir mudar porque não deu certo e aí em 2020 a gente tem um outro plano de ação, que pode não ser o mesmo em 2021, eu também acho que a gente tá sempre modificando e agregando valores." (Entrevista com a equipe da escola C).

Com esta ideia, as expectativas sobre o PPP aproximam-se de um processo permanente de reflexão, discussão e planejamento dos desafios reconhecidos pelos sujeitos da escola, bem como a busca de alternativas viáveis à efetivação da intencionalidade estabelecida no documento. Para que ele se realize, portanto, é necessário que se torne um ato contínuo entre considerações e avaliações acerca do que dispõe e suas implementações, como um estudo pormenorizado das possíveis ações para alcançar os princípios e objetivos propostos. Implícito está, neste processo, a intencionalidade das ações decorrentes, pois planeja-se para decidir melhor, racionalizar as ações em função das metas estabelecidas. No caso do planejamento escolar, que implica nas atividades e intenções para um número amplo de sujeitos, tanto para alunos como para servidores, espera-se que este 
ocorra de modo coletivo, ouvindo o maior número de pessoas em sintonia com uma lógica atenta para diagnósticos e discussões feitas em reuniões e conversas focadas em atender padrões mínimos de qualidade de ensino, que também auxiliarão na tomada de decisões.

A não utilização do PPP como base para o planejamento dos professores, pode evidenciar que nem todos compartilham das mesmas convicções, com divergências em algum, ou vários aspectos, desde a sua construção, incluindo a ideia de que "o papel aceita tudo", então pode-se escrever ali, um "belo" texto, mas que depois não poderá ser implementado, porque não revela as reais intenções de seus sujeitos. Disso decorre um problema para a equipe, que poderá estar muito entusiasmada em implementar um documento que efetivamente não corresponde aos anseios do grupo que o elaborou. $\mathrm{Na}$ entrevista com a equipe da escola $D$, há a exposição desse dilema, quando relatam a diferença entre trabalhar "como eu quero" ou como está proposto no PPP:

“(...) que tu vai ter que seguir essa proposta, que não vai ser naturalizado algumas práticas que, em outros ambientes, são naturalizadas, tipo a reprovação, a gente não naturaliza a reprovação, e isso é algo cultural dos professores que acham que a questão da reprovação, é algo sim que o aluno merece que ele precisa ter isso pra ele aprender a ser melhor, então ele traz isso e isso é uma questão que a escola não abre mão, a gente quer trabalhar, nós estamos trabalhando no processo lá do quadro, a gente ainda não diz que a reprovação não pode existir porque é um processo, mas a gente trabalha pra que isso não ocorra, então, os nossos conseIhos de classe são conselhos de classe, e são dentro dessa perspectiva." (Entrevista com a equipe da escola $D$, grifos nossos).

Neste mesmo sentido, observamos que ainda está presente nas escolas, a aceitação, a naturalização de práticas tradicionais, conservadoras, dissonantes do que é trazido no PPP, que ao menos no papel, apresenta-se democrático, crítico e reflexivo. Conforme acenado por Pinheiro (2013, p. 79), os eixos para a organização do trabalho pedagógico, "podem orientar a análise da implantação, do desenvolvimento e da manutenção de diferentes projetos escolares." Assim, a ampliação dos limites do que se efetivará como trabalho pedagógico possui alinhamento com a superação de frágeis práticas estabelecidas consensualmente, ou sobre atos isolados do processo de ensino e aprendizagem, que pela incipiência não permitem mudanças significativas no fazer da escola, seja em âmbito de gestão ou de docência.

Segundo Veiga (2013), o projeto político pedagógico, ao se constituir em processo democrático tem possibilidade de organizar o trabalho pedagógico escolar, modificando rotinas, eliminando relações competitivas e autoritárias, e "[...] diminuindo os efeitos fragmentários da divisão do trabalho que reforça as diferenças e hierarquiza os poderes de decisão." (VEIGA, 2013, p. 14). Obviamente, essa desagregação também chega aos setores da gestão, quando direção e supervisão escolares (como é o caso das escolas em análise) dividem o fazer cotidiano, exercendo muitas vezes, suas funções de maneira desarticulada 
uma da outra (LÜCK, 2014). Por isso é importante que gestores possam compreender a fragmentação, redimensionando e redefinindo pontos de conexão. Para a organização das ações de estudo e revitalização do PPP, necessitam caminhar pari passu com docentes, no movimento para uma real participação, que seja alicerçada, e impulsione o trabalho pedagógico coletivo. A realização dessa ação significa conseguir que o grupo de educadores chegue a pontos de partida (princípios) e de chegada (objetivos) comuns, envolvendo sistemas e práticas de gestão negociadas, unidade teórico-metodológica no trabalho docente, além de um sistema explícito e transparente de acompanhamento e avaliação (LIBÂNEO; OLIVEIRA; TOSCHI, 2012).

O projeto político-pedagógico permite que a realidade escolar seja objeto de reflexão, e que do confronto com as expectativas, novas prioridades sejam estabelecidas. Esse movimento não ocorre sem dificuldades, tanto de participação, como de compreensão do que efetivamente são decisões que impactarão no ensino e na aprendizagem, e nas relações entre os sujeitos da escola, de tal modo que acentua ainda mais a dificuldade de fazer a gestão:

\footnotetext{
Pensando no coletivo, não pensando só neles em um grupo em específico né, conseguem pensar no coletivo que é importante priorizar o coletivo [...] em julho a gente tava sentado, pensando as demandas do regresso, e uma das coisas pra nós óbvias, era que todos os professores queriam um quadro branco nas suas salas. Então a gente se organizou financeiramente e nós vamos botar em todas as salas. Daí numa das reuniões coletivas, surgiu - quem sabe vamos perguntar pra eles, e foi a metade só que queria. Então tu iria fazer um investimento nas férias, achando que em agosto todo mundo ia voltar feliz do quadro e a metade do grupo ia odiar. (Entrevista com a equipe gestora da escola D).
}

E a equipe segue problematizando acerca de suas aprendizagens, sobre escuta, planejamento, gestão democrática: "[...]eu acho que isso é algo que a gente vem num exercício de aprender, diários, esse problema não é só nosso, nós só estamos na gestão, nosso problema é pensar as ações e tudo mais, mas o grupo vai ter que se responsabilizar sobre isso." (Entrevista com a equipe da escola D). Desse modo, para a efetividade de um trabalho pedagógico, é necessário rever a organização da gestão escolar. Como responsáveis assumem e lideram a efetivação dessas estratégias (pedagógicas, administrativas e financeiras) no âmbito de suas atribuições. Acentua-se nesse sentido a necessidade de caracterizar da forma mais precisa possível os problemas que afetam o processo do trabalho pedagógico, de modo a favorecer a tomada de decisões realistas e exequíveis, verificando as relações entre elas (VEIGA, 2013).

Quando um gestor menciona que definições nem sempre são seguidas, pode estar evidenciando que isto ocorra por alguma das seguintes razões, ou até mesmo de modo combinado: ausência de participação ativa e efetiva dos diversos segmentos; descrédito diante daquilo que ficou definido no PPP, pois não representa a opinião de uma parcela 
importante dos docentes; o PPP tem o objetivo de suprir exigências burocráticas, visando apenas a formalização de um documento, que não necessariamente esteja imbuído de proposta construída e vivenciada em todos os momentos e por todos os envolvidos com o processo educacional; a relação estritamente hierarquizada entre gestores e docentes; desagregação entre os membros que compõem a gestão da escola; desconsideração do saber docente, entre outros.

E como uma possibilidade de superação diante disso, encontramos no depoimento da equipe gestora da escola $\mathrm{D}$, o emprego do PPP como princípio de uma construção coletiva dos diversos segmentos da escola e que, portanto, deve ser assumido por todos e todas do estabelecimento escolar. Assim, quando recebem um "novo" profissional, ele é apresentado ao projeto da escola e, caso não concorde, então, é convidado a rever suas posições e, no limite, deixar a escola.

As perguntas norteadoras que nos trouxeram até aqui, cercam um horizonte que tenta compreender o PPP, que revela fundamental a participação de todos, nas diversas etapas e instâncias, tanto para a proposição como para a implementação de ações visando a concretizar o projeto educativo da escola. Para a construção de um trabalho pedagógico, compreendemos que tanto o planejamento das atividades escolares quanto a formação reflexiva em serviço podem ser considerados instrumentos importantes do fazer educativo, e de tal modo ajudar na viabilização do trabalho pedagógico, especialmente se considerarmos a relação intrínseca entre os profissionais da gestão e da docência e os documentos - permitindo ao mesmo tempo a reflexão acerca das ações empreendidas e resultados obtidos.

Os gestores percebem em diversos momentos a dificuldade que a escola possui em estabelecer consensos, quando se trata de discorrer sobre currículo, avaliação, exigências de aprendizagem etc. E para além disso, a dificuldade de acordos entre os pares, e entre professores e gestores, apoiam-se em crenças mais individualizadas que geralmente se distanciam das convergências para os mesmos objetivos.

A escola, por isso, representa um espaço muito particular, rico e profícuo para que possam ser observados diversos fenômenos, como participação, modos de gestão, trabaIho pedagógico, dentre outros. O modo como estes serão praticados ou não encontra, a nosso ver, mais respostas pelas alternativas produzidas pelos sujeitos e atores em contexto escolar, do que por fidelidade ou infidelidade às regras e normas estabelecidas.

\section{CONSIDERAÇÕES FINAIS}

Como objetivo central desse texto estava a análise do projeto político-pedagógico sua reflexão, os obstáculos para sua implementação, sua relação com o contexto da gestão da escola e sua realização por meio de um trabalho pedagógico efetivado além das ações 
que se desenvolvem na sala de aula (FERREIRA, 2018), ou seja, aquele que se estabelece entre os docentes que compõem a equipe gestora da escola e os demais professores.

Aqui, inexiste a expectativa de identificar fórmulas mágicas que serão aplicadas para a melhoria imediata da qualidade da educação, bem como da solução rápida de seus problemas. Contudo, diante das reflexões enunciadas e os riscos de nunca serem compreendidas e atendidas, falamos de algo concreto, real, propício de percalços, retomadas e redirecionamentos. Esse estado de coisas faz-nos questionar o desenvolvimento dos PPPs instituídos e como podem auxiliar no trabalho pretendido pelas escolas. São recorrentes as vinculações feitas entre a gestão escolar e a burocracia administrativa, bem como da necessidade que todos os gestores atuem no campo pedagógico, ou seja, em sintonia com os objetivos educacionais, com a função social da escola. É possível, portanto, que em meio a esse conjunto de relações, fazeres e atribuições se evidencie a falta de articulação entre o planejado e o realizado, especialmente na conexão entre o PPP e o trabalho pedagógico.

Ação e reflexão e vice-versa, portanto, formam o ato comprometido (FREIRE, 1979) com o projeto da escola e sua gestão. E para que isso se efetive são necessários: tempo, planejamento coletivo e formação, pois é imperativo contar com os atores da escola para que as mudanças e suas intenções ocorram. Estudos e pesquisas na área (PIMENTA, 2014; TARDIF; LESSARD, 2011), afirmam que os professores são profissionais essenciais nos processos de mudança das sociedades. Se forem deixados à margem, as decisões pedagógicas e curriculares, por mais interessantes que possam parecer, não se efetivarão. Por isso, é preciso investir com eles, a partir de seu saber, na sua formação e no seu desenvolvimento profissional, eis aqui, alguns elementos para pesquisas futuras.

As expectativas para que a escola se apresente inovadora podem encontrar guarida no embate aos problemas estruturais que ela apresenta, bem como necessitam estar alinhadas com o planejamento e com a condução de um PPP condizente com suas necessidades, por meio do trabalho pedagógico e coletivo entre gestores e docentes. 


\section{REFERÊNCIAS}

AZEVEDO, Janete Maria Lins de. O projeto político-pedagógico no contexto da gestão escolar. In: Retratos da escola. Boletim 12 - Salto para o Futuro. Brasil: MEC, 2005. Disponível em: https:// bit.ly/3hn7kTK. Acesso em: 25 jun. 2020.

BRANDÃO, Carlos Rodrigues. O que é educação. 33. ed. São Paulo: Brasiliense, 1995.

BRASIL. Lei n. 9394, de 20 de dezembro de 1996. Lei de Diretrizes e Bases da Educação Nacional. Brasília, 1996.

CANÁRIO, Rui. Estabelecimento de ensino: a inovação e a gestão de recursos educativos. In: NÓVOA, A. (Org.). As organizações escolares em análise. Lisboa: D. Quixote/IIE, 1992.

CARBONELL, Jaume. A aventura de inovar: a mudança na escola. Porto Alegre: Artmed. 2002.

COLOGNESE, S. A.; MÉLO, J. L. B. de. A técnica de entrevista na pesquisa social. Cadernos de Sociologia, Porto Alegre, v. 9, p. $143-159,1998$.

COSTA, Daianny Madalena. O projeto político-pedagógico - considerações acerca da gestão para a autonomia da escola. Reflexão e Ação. Santa Cruz do Sul, v. 29, n. 1, p. 218-232, jan./abr. 2021. p. 218-232. Disponível em: https://online.unisc.br/seer/index.php/reflex/index Aceso em 28 abr. 2021.

FERREIRA, Liliana Soares. Trabalho Pedagógico na Escola: do que se fala?. Educ. Real. Porto Alegre, v. 43, n. 2, p. 591-608, abr./jun. 2018.

FREIRE, Paulo. Educação e Mudança. Rio de Janeiro: Paz e Terra, 1979.

FREIRE, Paulo. Pedagogia do oprimido. 17. ed. Rio de Janeiro : Paz e Terra, 1987.

FREIRE, Paulo. Pedagogia da autonomia: saberes necessários à prática educativa. 25. ed. Rio de Janeiro : Paz e Terra, 2002.

GADOTTI, Moacir. FREIRE, Paulo. GUIMARÃES, Sérgio. Pedagogia: diálogo e conflito. 5. ed. São Paulo: Cortez; Autores Associados, 2000.

GANDIN, Danilo; GANDIN, Luís Armando. Temas para um projeto político-pedagógico. 12 ed. Petrópolis, RJ: Vozes, 2011.

GHEDIN, Evandro; FRANCO, Maria Amélia Santoro. Questões de método na construção da pesquisa em educação. São Paulo: Cortez, 2008.

GOMES, Romeu. Análise e interpretação de dados de pesquisa qualitativa. In: MINAYO, Maria Cecília de Souza; DESLANDES, Suely Ferreira: GOMES, Romeu. Pesquisa social: teoria, método e criatividade. Petrópolis, RJ: Vozes, 2016. p. 72-95.

IMBERNÓN, Francisco. Formação docente e profissional: formar-se para a mudança e a incerteza. 9. ed. São Paulo : Cortez, 2011 
LIBÂNEO, José Carlos; OLIVEIRA, João Ferreira de; TOSCHI, Mirza Seabra. Educação Escolar: políticas, estrutura e organização. 10. ed. São Paulo: Cortez, 2012.

LIBÂNEO, José Carlos. Organização e gestão da escola: teoria e prática. 5. ed. Goiânia: MF Livros, 2008.

LÜCK, Heloísa. Gestão educacional: uma questão paradigmática. 11. ed. Petrópolis: Vozes, 2014. (Série Cadernos de gestão).

MINAYO, Maria Cecília de Souza. O desafio da pesquisa social. IN: MINAYO, Maria Cecilia de Souza (Org.); DESLANDES, Suely Ferreira. Pesquisa Social: Teoria, Método e Criatividade. 26 ed. Petrópolis: RJ, Vozes, 2016. (Série Manuais acadêmicos).

NÓVOA, António. Para uma análise das instituições escolares. In: NÓVOA, António. (Coord.). As organizações escolares em análise. Lisboa: Dom Quixote, 1992.

PARO, Vitor Henrique. Crítica da estrutura da escola. São Paulo: Cortez, 2011.

PARO, Vitor Henrique. Diretor escolar: educador ou gerente? São Paulo: Cortez, 2015.

PIMENTA, Selma Garrido. Apresentação da coleção. In: STRECK, et al. Educação popular e docência. 1. ed. São Paulo: Cortez. 2014. (Coleção docência em formação: Educação de jovens e adultos).

PINHEIRO, Maria Eveline. A ação coletiva como referencial para a organização do trabalho pedagógico. In.: VEIGA, IIma Passos e RESENDE, Lúcia M. G. de (orgs.). Escola: espaço do projeto político-pedagógico. 17. ed. Campinas: Papirus, 2013.

RUSSO, Miguel Henrique. Trabalho e administração da escola: desenvolvimento e apropriação do sentido que assumem no processo de produção pedagógica. Revista Brasileira de Política e Administração da Educação - Periódico científico editado pela ANPAE, [S.I.], v. 27, n. 3, mar. 2011.

TARDIF, Maurice; LESSARD, Claude. O trabalho docente: elementos para uma teoria da docência como profissão de interações humanas. 6. ed. Petrópolis, RJ : Vozes. 2011.

THURLER, Mônica Gather. Inovar no interior da escola. Porto Alegre: Artmed, 2001.

VASCONCELLOS, Celso S. Planejamento: Projeto de Ensino-Aprendizagem e Projeto Político-Pedagógico, 15. ed. São Paulo: Libertad, 2006.

VEIGA, IIma Passos Alencastro. Projeto político-pedagógico da escola: Uma construção coletiva. In: VEIGA, IIma Passos Alencastro (Org.). Projeto político-pedagógico da escola: Uma construção possível. 29 ed. Campinas: Papirus, 2013. p. 11-35. (Coleção Magistério: Formação e Trabalho Pedagógico).

VEIGA, IIma Passos; RESENDE, Lúcia M. G. de (Org.). Escola: espaço do projeto político- pedagógico. 17. ed. Campinas: Papirus, 2013. 